\title{
PREDICTION OF SHEAR RESISTANCE FACTOR IN FLAT SLABS DESIGN USING CRITICAL PERIMETER OF SUPPORTING COLUMNS
}

\author{
F. O. Idagu ${ }^{1,}{ }^{*}$, N. M. Ogarekpe ${ }^{2}$ and T. I. Ugama ${ }^{3}$ \\ 1,2DePt. of Civil Engineering, Cross River University of TEChNology, CAlabar, Cross River State. NigERIA

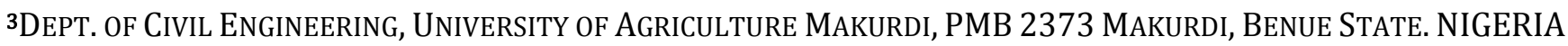 \\ Email addresses:11dagufrancis@yahoo.com,2nkpaogarekpe@gmail.com,3ugamaterry@yahoo.com
}

\begin{abstract}
The distribution of shear stresses at the slab-column connection of flat slabs become non-uniform in the presence of unbalanced moment. The shear resistance $(\beta)$ factor is used to account for this distribution of shear stresses due to the transfer of unbalanced moment at the slab-column connections. The provisions of the American, Canadian, European and Model codes, regarding the transfer of unbalanced moment at slab-column connections of flat slabs are compared. The relationship of $\beta$-factor to the ratio of critical perimeter to the control perimeter of an internal column have been plotted as a simplified approach and additional approximate $\beta$ factors have been found for an internal corner column and various locations of cantilevered edge, corner and internal corner columns encountered in practice by engineers. These additional approximate $\beta$ factors have been proposed for inclusion in European code for situations where adjacent spans do not differ by more than $25 \%$.
\end{abstract}

Keywords: Flat Slabs, Punching Shear, Codes Formulations, Unbalanced Moment, Eccentricity.

\section{INTRODUCTION}

Flat slabs are beamless slabs, implying that they are directly supported by columns without beams. Lateral stability for flat slab structures does not depend on frame action. Flat slabs may have uniform or varied thickness depending on the designer's choice. Flat slabs are economical, easy to construct, have flexibility in room layout, ease of installation of services and provide better lighting of floors for industrial buildings and multi-storey parks. However, brittle failure can occur as a result of punching shear and its stability does not depend on frame action.

The shear resistance factor or $\beta$-factor is used for the distribution of shear forces when there is an unbalanced moment transfer and it is expressed as in Equations (1) and (2) of the European code [5] in the relevant Clauses 6.38 and 6.39 respectively.

$$
\begin{aligned}
& \beta=1+\mathrm{k} \frac{\mathrm{M}_{\mathrm{Ed}}}{\mathrm{V}_{\mathrm{Ed}}} \frac{\mathrm{U}_{1}}{\mathrm{~W}_{1}} \\
& v_{E d}=\beta \frac{\mathrm{V}_{\mathrm{Ed}}}{\mathrm{U}_{1} \mathrm{~d}}
\end{aligned}
$$

Where: The parameter $\frac{\mathrm{M}_{\mathrm{Ed}}}{\mathrm{V}_{\mathrm{Ed}}}$ represents the eccentricity, $\mathrm{M}_{\mathrm{Ed}}$ and $\mathrm{V}_{\mathrm{Ed}}$ are the design bending moment and shear force respectively, $\mathrm{K}$ is a coefficient dependent on the ratio between the column dimensions $c_{1}$ and $c_{2}$. $U_{1}$ is the control perimeter, $\mathrm{d}$ is the effective depth of slab and $V_{E d}$ is the applied shear stress. $W_{1}$ corresponds to a distribution of shear. Figure 1 shows the recommended [5] values of $\beta$-factor.

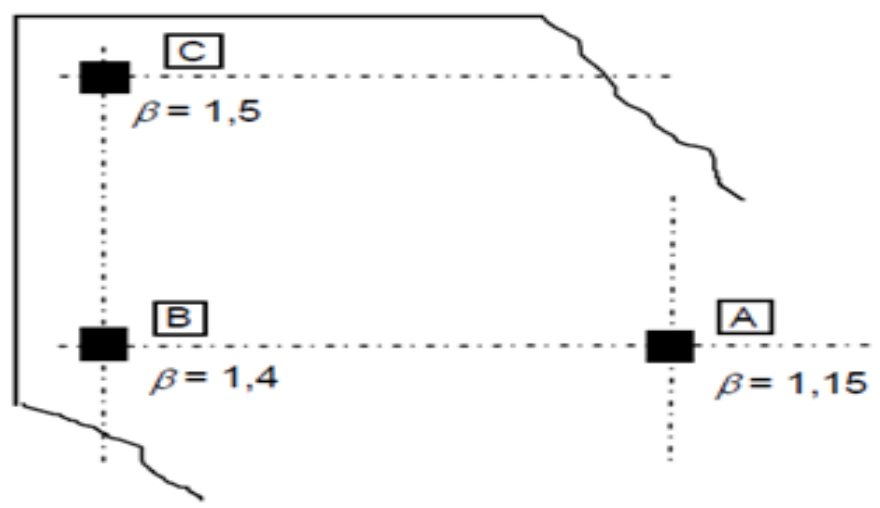

Figure 1: Recommended Values of $\beta$ [5]

\subsection{Background of Study}

\subsubsection{Comparison of Design Codes}

(a) American code ACI 318-08

When there is an unbalanced moment transfer between slab and column at connections, part of the moment shall be transferred by flexure while the remainder will be transferred by eccentricity of shear [1]. Also, it is formulated that $\Upsilon_{\mathrm{f}} \mathrm{M}_{\mathrm{u}}$ shall be transferred by flexure within $1.5 \mathrm{~h}$ from the face of column where $\mathrm{h}$ is the thickness of the slab. $\gamma_{\mathrm{f}}$ is a factor used to determine the 
unbalanced moment transferred by flexure at the slab column connections and is formulated [1] as in Equation (3).

$$
\gamma_{\mathrm{f}}=\frac{1}{1+(2 / 3) \sqrt{\mathrm{b}_{1} / \mathrm{b}_{2}}}
$$

Where $b_{1}$ is the dimension of the critical section measured in the direction of the span for which moments are determined in $\mathrm{mm}, \mathrm{b}_{2}$ is the dimension of the critical section measured in the direction perpendicular to $b_{1}$ in $\mathrm{mm}, \gamma_{\mathrm{v}} \mathrm{M}_{\mathrm{u}}$ which is the remainder of the unbalanced moment transferred by shear shall be transferred by eccentricity of shear about the centroidal axis of the critical perimeter depicted in Clause 11-37American [1] code.

$$
\gamma_{\mathrm{v}}=\left(1-\gamma_{\mathrm{f}}\right)
$$

Where $\gamma_{\mathrm{v}}$ is the factor used to determine the unbalanced moment transferred by eccentricity of shear at the slab column connections.

\section{(b) Model Code (2010)}

The Model [4] code specifies that for flat slabs where lateral stability does not depend on frame action and adjacent spans do not differ by more than $25 \%$, a reduction factor $k_{e}$ should be applied to the critical perimeter as follows:

$k_{e}$ is the 0.65 for corner column position, $k_{e}$ is the 0.70 for edge column position and $k_{e}$ is the 0.90 for internal column positions. In the presence of unbalanced moment, the reduction factor should be taken as in Equation (5), which is explained in Clauses $7.3-38$ of the Model [4] code.

$$
\mathrm{k}_{\mathrm{e}}=\frac{1}{1+\mathrm{e} / \mathrm{b}}
$$

Where $e$ is the eccentricity, $\mathrm{M}_{\mathrm{Ed}} / \mathrm{V}_{\mathrm{Ed}}$, and $\mathrm{b}$ is the diameter of a circle with equal surface as the support region.

\subsection{Punching Shear Resistance by Design Codes}

A sample size $400 \mathrm{~mm} \times 400 \mathrm{~mm}$ and assumed effective slab depth of $260 \mathrm{~mm}$ was used in the empirical equations of the American [1], Canadian [3], European [5] and Model [11] codes to arrive at the relationship depicted in Figure 2. The same square column with effective slab depth of $300 \mathrm{~mm}$ is used to arrive at the relationship in Figure 3. It can be seen from the relationships formulated that the European [5] code responds slowly to increases in concrete strength, while the other codes respond rapidly to increases in concrete strength. This is due to the adoption of the cube root of concrete strength by the European [5] code and square root of concrete strength by other codes in the empirical equations to estimate punching shear strength of flat slabs. Furthermore, the European [3] code shows tremendous response to variation in the reinforcement ratio while the punching shear resistance estimated by the American [1], Canadian [3] and Model [11] codes do not depend on the reinforcement ratio. This is evident as shown in Figure 3 with constant values of punching shear resistance shown as horizontal lines irrespective of increases in reinforcement ratio. However, the European [5] code provides less value of punching shear resistance at low reinforcement ratios and higher values at high reinforcement ratios. The punching shear strength of concrete flat slabs is expressed as by the various design codes as:

(i) Clause $11-13$ of American code [1]:

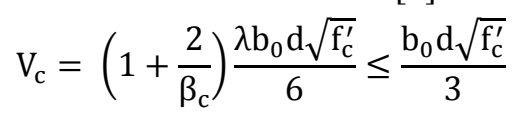

(ii) European Code [5]:

$$
\mathrm{V}_{\mathrm{Rd}, \mathrm{c}}=\left(0.18 / \gamma_{\mathrm{c}}\right) \mathrm{K}\left(100 \rho_{\mathrm{l}} \mathrm{f}_{\mathrm{ck}}\right)^{1 / 3}
$$

(iii) Canadian code [3]:

$$
\mathrm{V}_{\mathrm{c}}=0.4 \lambda \phi_{\mathrm{c}} \sqrt{\mathrm{f}_{\mathrm{c}}^{\prime}}
$$

(iv) Clause 7.3 - 40 Model code [11]:

$$
\mathrm{V}_{\mathrm{Rd}, \mathrm{c}}=\mathrm{k}_{\Psi} \frac{\sqrt{\mathrm{f}_{\mathrm{ck}}}}{\gamma_{\mathrm{c}}} \mathrm{b}_{0} \mathrm{~d}_{\mathrm{v}}
$$

Where $b_{0}$ is the critical or control perimeter. $f_{c}^{\prime}$ is the compressive cylinder strength in $\mathrm{N} / \mathrm{mm}^{2}$ or in $\mathrm{in}^{2} \beta_{\mathrm{c}}$ is the ratio of the long to short side of the loaded area $\lambda$ is the strength reduction factor for shear, usually taken as 0.85 , while $\alpha_{s}$ is taken as 40 for interior columns, 30 for edge columns and 20 for corner columns.

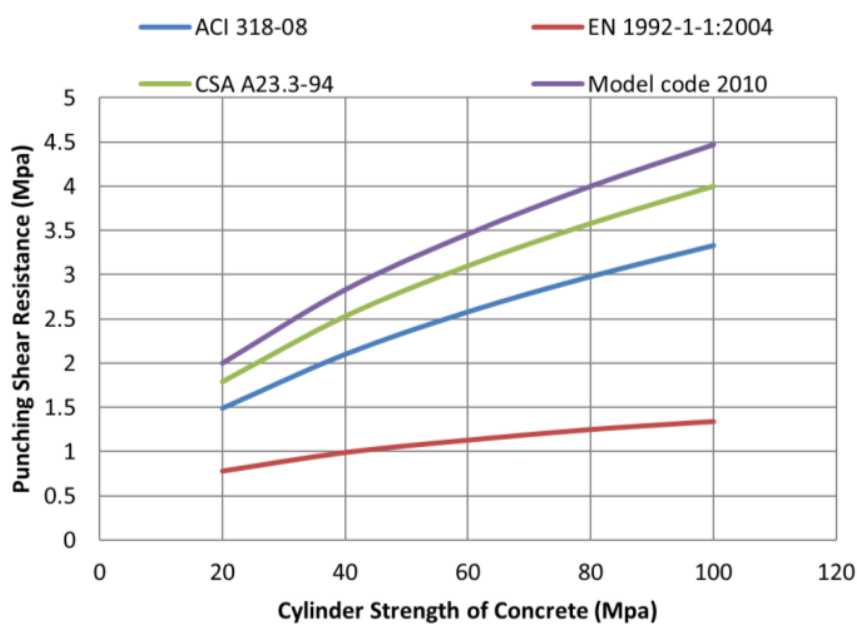

Figure 2: Relationship of Punching Strength Without Shear Reinforcement to Cylinder Strength of Concrete ( $\rho=0.5 \%)$

The critical perimeter is also estimated in different ways by the design codes. The American [1] code and Canadian code takes the critical or control perimeter as $0.5 \mathrm{~d}$ from the face of column, the Model [11] code takes it as $0.5 \mathrm{~d}_{\mathrm{v}}$ from face of column while the European [5] code takes it as $2 \mathrm{~d}$ from the face of column. As a result, the critical perimeter from the European [5] code is higher than the critical perimeter from the American [1] code, Canadian [3] code and Model [11] code. However, a higher critical perimeter implies a smaller stress while a smaller critical 
perimeter implies a higher stress. This is evident as shown in Figure 2 as the threshold shear stress for European [5] code is less than those of the American [1] code, Canadian [3] code and the Model [11] code.

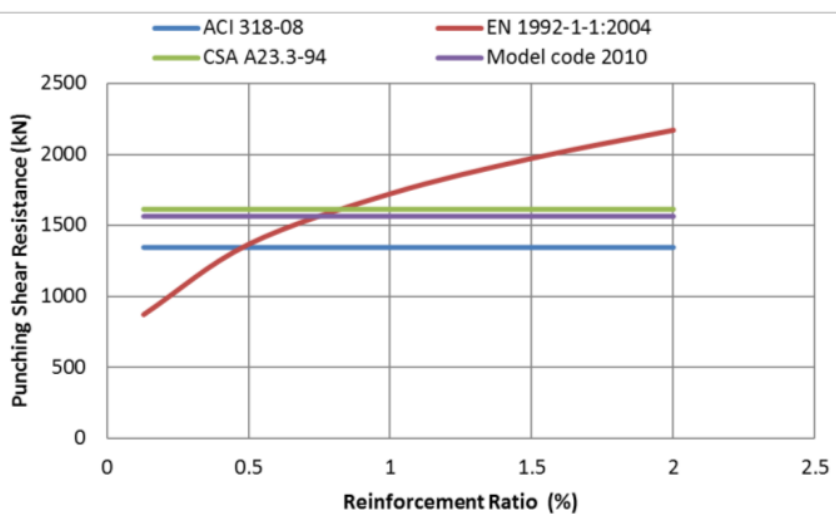

Figure 3: Relationship of Punching Strength without Shear Reinforcement to Cylinder Strength of Concrete $(\rho=0.5 \%)$

\section{LITERATURE REVIEW}

Series of researches carried out in the past have shown that punching shear failure can be brittle and lead to progressive collapse. Kruger [8] carried out an experimental and analytical study of interior columns subjected to punching in the presence of an unbalanced moment. Unbalanced moment occurs in flat slabs due to unequal spans on either sides of column as well as unsymmetrical loading of adjacent spans. Kruger [8] stated that it can also occur as a result of differences of temperature or differential creep between two adjacent floors resulting in differential displacement of the top and bottom of the columns. Punching shear resistance decreases in the presence of an unbalanced moment at the slab - column connection.

In the experiment, seven square flat slabs of size $3 \mathrm{~m}$ by $3 \mathrm{~m}$ and thickness $150 \mathrm{~mm}$ with a square column of size $300 \mathrm{~mm}$ by $300 \mathrm{~mm}$ were tested. The characteristic strength of the concrete used was $35 \mathrm{Mpa}$. The loads were applied vertically downward, with the hydraulic ram located in such a manner to provide eccentricity which induced the vertical force and moment in the column at the same time. The slab was simply supported on knife edge which was fixed on steel beams so that its edges were free to lift. The eccentricity of loading was varied for the seven specimens. Some of the specimens were provided with shear reinforcement while others were not. The flexural reinforcement ratio was $1 \%$ for the slabs without punching shear reinforcement and 1.3\% for those with shear reinforcement. The shear reinforcement was stirrups and two headed studs used independently. Kruger [8] showed that the maximum deformations in the tests were controlled by the hydraulic ram and the loads were applied in steps of $40 \mathrm{kN}$. Instruments used were strain gauges, displacement sensors and force sensor on the jack and inclinometers on the columns. The measurements from gauges and sensors were recorded every minute on the computer. From the results, Kruger [8] showed that moment due to eccentricity of the load on the column has significant effect in decreasing the punching shear resistance of flat slab.

The results also show that unbalanced moment account for small decrease of the ultimate load capacity for internal columns when loading is unsymmetrical. It was concluded that large eccentricities can cause a reduction in punching shear resistance above $30 \%$.

Kheyroddin [7], observed that the reduction in ultimate load is about $26 \%$ for an eccentricity of $150 \mathrm{~mm}$ and $38 \%$ for an eccentricity of $300 \mathrm{~mm}$. To investigate this phenomenon, a special shape was provided to the column stub which made it possible to apply the axial load to the column with an eccentricity about $150 \mathrm{~mm}$ and $300 \mathrm{~mm}$. Kheyroddin [7] noticed that the steel volume ratio in the central zone of the models increased up to $30 \%$. The steel volume ratio for central zone of strengthened model was $3.64 \%$ and for peripheral zone was $2.8 \%$. Kheyroddin [7] concluded that the ultimate load capacity of flat slab is influenced by eccentricity. The decrease in ultimate load is about $26 \%$ for an eccentricity of $150 \mathrm{~mm}$ and $38 \%$ for eccentricity of $300 \mathrm{~mm}$. Strengthened models increase ultimate load up to $20-28 \%$ depending on the value of eccentricity.

Broms [2] carried out an extensive study on the shear strength of slab - column connections. Significant variable in his test was eccentricity which is an important consideration in this research. He also varied the steel strength, concrete strength and column sizes. Slabs M8 and M10 had large eccentricities and were supplied with negative reinforcements to prevent negative moment type of failure which was noticed in specimens M4 and M5. Slabs M2 to M5 failed before yielding of reinforcements. Broms [2] assumed that the critical section was adjacent to the column axis and that the shearing stresses are uniform across the plane of symmetry.

Megally [9] reported test results of three shear units which were pre-assembled. The first specimen consisted of two straight wires, the second comprised $6 \mathrm{~mm}$ shear studs which were welded to steel strip while the third sample consisted of welded wire fabric which were cut and bent to form shear reinforcements. Their reports showed that these shear reinforcements were capable of enhancing the ductility and shear strength of flat slabs provided they are properly anchored.

The test results show clearly the reduction in shear capacity of flat slabs due to eccentricity of loading resulting from unbalanced moment. 

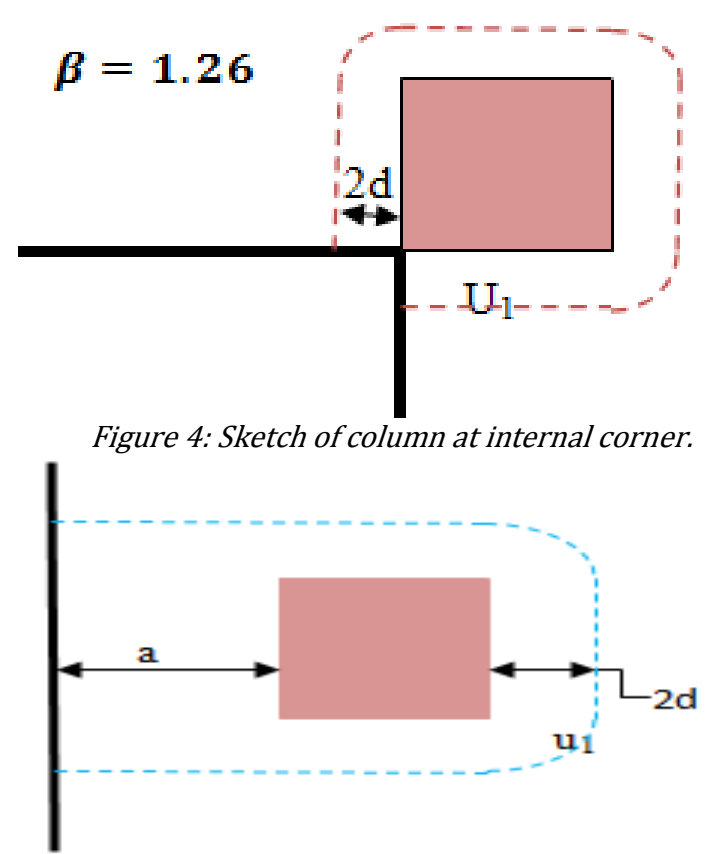

Figure 5: Sketch of column at cantilevered edge

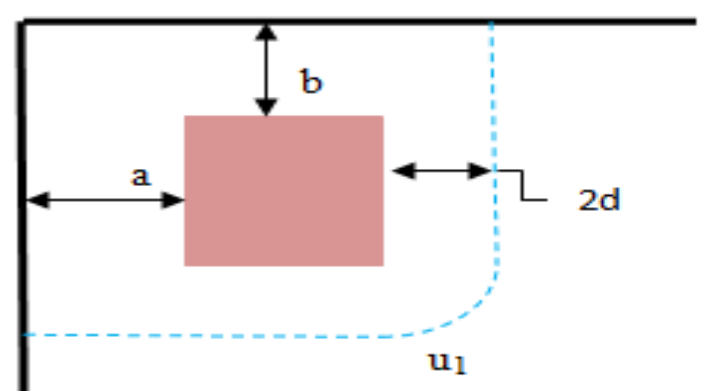

Figure 6: Sketch of column at cantilevered corner.

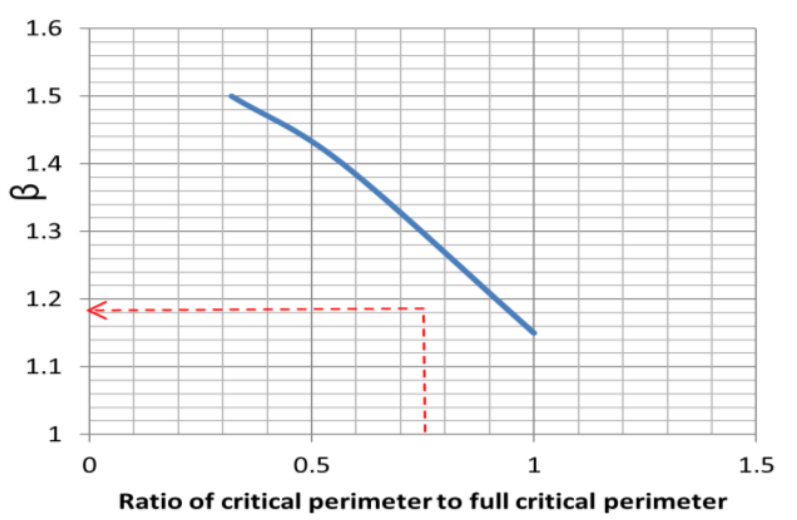

Figure 7: Relationship of $\beta$-factors to ratio of critical perimeter to full critical perimeter for columns locations.

The test by Megally [9] also shows the effect of slab rotation on the shear capacity of flat slabs. It was shown that, the greater the slab rotation, the lower the shear capacity of the slab. The ultimate shear capacity recorded from the tests were checked with shear capacity values obtain from the American [2] code predictions to validate results from the tests. Elgabry [4] found the ratio of experimental test results to the values obtained by Model [11] code as 1.16, while Hawkins [6] found the ratio of experimental test results to the values obtained by Model [11] code as 1.24.

\section{METHODOLOGY}

The control perimeters according to the European [5] code are found as follows:

For internal column,

$$
U_{1}=2\left(c_{1}+c_{2}\right)+4 \pi d
$$

For edge column,

$$
U_{1}=2 c_{1}+c_{2}+2 \pi d
$$

For corner column,

$$
U_{1}=c_{1}+c_{2}+\pi d
$$

It can be shown that at an internal corner as shown in Figure 5,

$$
U_{1}=2\left(c_{1}+c_{2}\right)+3 \pi d
$$

A typical square column of $400 \mathrm{~mm}$ sides with an effective slab depth of $300 \mathrm{~mm}$ has been used and Equations 10, 11 and 12 were applied to find the corresponding critical perimeters for internal, edge and corner columns as $5.37 \mathrm{~m}, 3.09 \mathrm{~m}$ and $1.74 \mathrm{~m}$ respectively. The ratios of control perimeter of section considered to the full perimeter of an internal column were found as $1.00,0.57$ and 0.32 for internal, edge and corner columns respectively. The $\beta$ factors of 1.15 for internal column, 1.4 for edge column and 1.5 for corner columns earlier obtained for situations where the spans does not differ more than $25 \%$ were plotted against the critical perimeter ratio as shown in Figure 7. Equation 13 was then used to calculate the critical perimeter for an internal corner column which is obtained to be $4.43 \mathrm{~m}$ and the ratio of this perimeter to the critical perimeter of an internal column was found as 0.82 . The value of $\beta$ was readfrom the relationship in Figure 7 as 1.26 for an internal corner column.

Considering a cantilevered edge column as shown in Figure 6, let the distance of the column from the edge be denoted by (a) so that for (a) equals zero, $\beta=1.4$ as already established by European [5] code.

The column details used for plotting the graph in Figure 7 is used throughout to enable the values of $\beta$ to be read directly from Figure 7.

Same procedure is adopted in all cases for cantilevered corner and internal corner columns and results obtained are summarized in table 1, 2 and 3.

Table 1: $\beta$ Factors for cantilevered edge columns

\begin{tabular}{llllll}
\hline $\mathrm{a}$ & 0 & $\mathrm{~d}$ & $1.5 \mathrm{~d}$ & $2 \mathrm{~d}$ & $>6 \mathrm{~d}$ \\
\hline$\beta$ & 1.4 & 1.33 & 1.30 & 1.29 & 1.15 \\
\hline
\end{tabular}

Table 2: $\beta$ Factors for cantilevered corner columns

\begin{tabular}{lllllll}
\multicolumn{7}{c}{ Table 2: $\beta$ Factors for cantilevered corner columns } \\
\hline $\mathrm{a}$ & 0 & $\mathrm{~d}$ to $2 \mathrm{~d}$ & $\mathrm{D}$ & $1.5 \mathrm{~d}$ to $2 \mathrm{~d}$ & $2 \mathrm{~d}$ & $>6 \mathrm{~d}$ \\
\hline $\mathrm{b}$ & 0 & $\mathrm{~d}$ & $\mathrm{D}$ & $\mathrm{d}$ & $2 \mathrm{~d}$ & $>6 \mathrm{~d}$ \\
$\beta$ & 1.5 & 1.47 & 1.46 & 1.45 & 1.43 & 1.15 \\
\hline
\end{tabular}

Table 3: $\beta$ Factors for cantilevered internal corner columns

\begin{tabular}{llllll}
\hline $\mathrm{a}$ & 0 & $\mathrm{~d}$ & $\mathrm{D}$ & $1.5 \mathrm{~d}$ & $>6 \mathrm{~d}$ \\
\hline $\mathrm{b}$ & 0 & 0 & $\mathrm{D}$ & 0 & $>6 \mathrm{~d}$ \\
$\beta$ & 1.26 & 1.24 & 1.18 & 1.21 & 1.15 \\
\hline
\end{tabular}




\section{RESULTS AND DISCUSSION}

The $\beta$-factors for different eccentricities have been estimated from Equation (1) for internal for internal, edge and corner columns based on the European [5] code and results presented in the graphs in figure 8, 9 and 10. Where adjacent spans differ by more than $25 \%$, the $\beta$ factors should be found from Equation 1.

Where adjacent spans do not differ by more than $25 \%$, an eccentricity of $138 \mathrm{~mm}$ from the European [5] code and $115 \mathrm{~mm}$ from Model [11] code gave an approximate $\beta$ factor of 1.15 for internal column as shown in Figure 8. For an edge column, an eccentricity of $381 \mathrm{~mm}$ from the European [5] code and 287mm from Model [11] code gave an approximate $\beta$ factor of 1.40 as shown in Figure 9. For corner column, an eccentricity of $450 \mathrm{~mm}$ from the European [5] code and 350mm from the Model [11] code gave an approximate $\beta$ factor of 1.50 as shown in Figure 10.

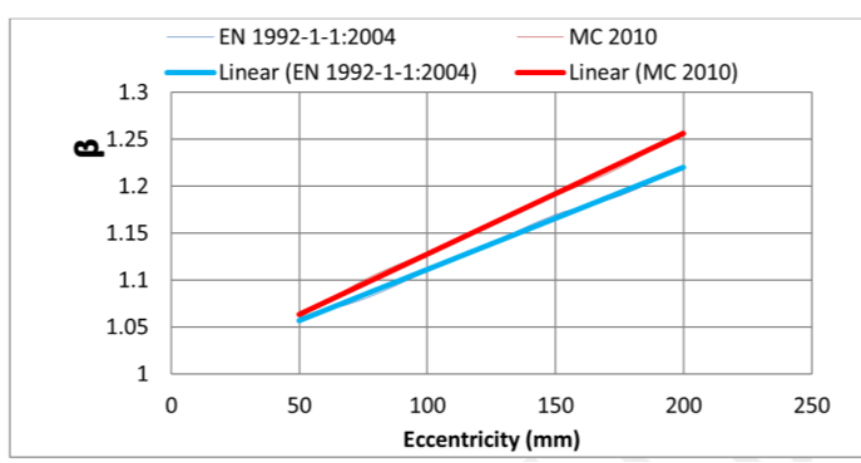

Figure 8: Relationship of $\beta$ - factors to eccentricity of internal columns.

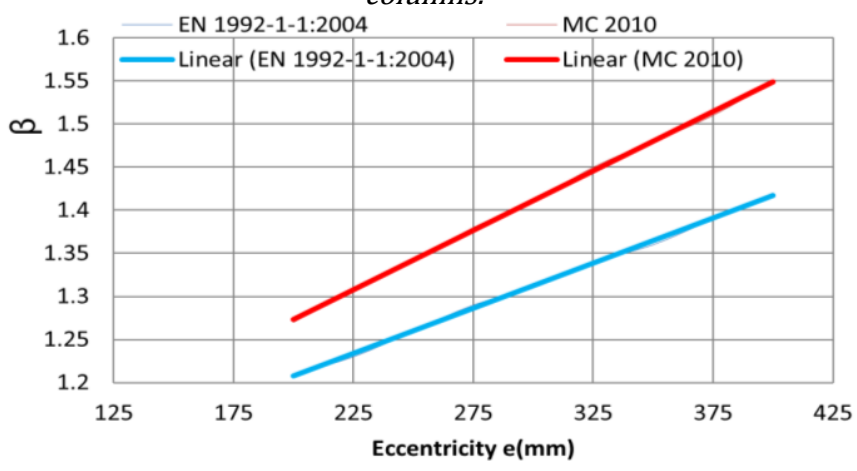

Figure 9: Relationship of $\beta$ factors against eccentricity for edge

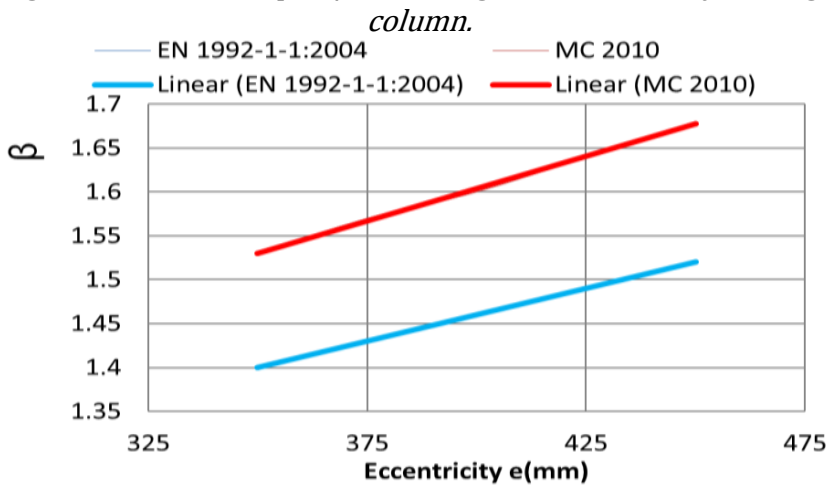

Figure 10: Relationship of $\beta$ factors against eccentricity for corner column.

\section{CONCLUSIONS}

The predictions of punching shear resistance of flat slabs by all design codes are empirical. The compressive strength of concrete is the major parameter for estimating the punching shear resistance by all design codes. The American [1], Canadian [3] and Model [11] codes uses the square root of the compressive strength of concrete while the European [5] code uses the cube root of concrete compressive strength. As a result of this, the response of the American code, Canadian code and Model [11] code to increase in concrete strength is higher while the European [5] code responds slowly to increase in concrete strength as shown in Figure 2.

Where there is an unbalanced moment transfer, the American [1] code and the Canadian [3] code specifies that a fraction $\gamma_{f}$ of the unbalanced moment is transferred by flexure while the remainder of unbalanced moment $\gamma_{v}$ is transferred by eccentricity of shear. The European [5] code and the Model [11] code makes similar provisions for the transfer of unbalanced moment at the slab - column connections with empirical equations to provide $\beta$ factors which increases the calculated shear force to account for the non-uniform distribution of shear.

The critical perimeter which is the most relevant factor in the determination of $\beta$ factor has been used in a simplified approach of a graph to produce additional $\beta$ factors for internal corner columns and cantilevered corner, internal corner and edge columns.

In general, it can be concluded that the European [5] code and Model [11] code uses different approaches in estimating the $\beta$ factors but produces similar results with values from Model [11] code slightly greater than that of the European [5] code. The additional $\beta$ factors provided in table 1,2 and 3 are based on simplified approach of the graph in Figure 7 from empirical equations of the European [5] code. These additional $\beta$ factors have not been compared with experimental results due to time constraint. It is therefore recommended for future research that actual experiments be conducted and the results obtained should be compared with values provided in this work to validate results for subsequent inclusion in the European [5] code. The additional $\beta$ factors provided in this work are approximate values which are based on the condition that adjacent spans or loading conditions do not differ by more than $25 \%$. Where adjacent spans or loading conditions differ by more than $25 \%$, Equation (1) should be applied to calculate the $\beta$ factors.

\section{REFERENCES}

[1] American Concrete Institute : Building code requirement for structural concrete. Farmington Hills, ACI. 2008. 
[2] Broms, C. Concrete flat slabs and footing design method for punching and detailing for ductility. Stockholm, Royal Institute of Technology. 2005.

[3] Canadian code (CSA A23.3-94): Design of Concrete Structures, CSA.

[4] Elgabry, A Moment transfer by shear in slab-column connections, ACI journal of structural engineering, volume 93, 187-196. 1996.

[5] Eurocode 2 (EN-1992-1-1:2004): Design of concrete structures part 1: General rules for buildings. British Standard Institution. 2004.

[6] Hawkins, N and Corley, W Transfer of unbalanced moment and shear from flat plates to columns. ACI journal of structural engineering, volume 30, no.7, 147-176. 1971.
[7] Kheyroddin, A, Hoseini, S. R and Nadepour, H Numeical analysis of slab-column connections. Journal of applied sciences, volume 8, 420-431. 2008.

[8] Kruger, G, Burdet, $\mathrm{O}$ and Favre, R Punching test on RC flat slabs with eccentric loading. $\mathrm{PhD}$ symposium in civil engineering, Budapest, Hungary, 1-8. 1998.

[9] Megally, S and Ghali, A Design for punching shear in concrete: critical review of the Canadian standard CSA A23.3-94. Canadian journal of civil engineering, volume 23, 444-456. 1996

[10] Megally, S and Ghali, A Punching of concrete slabs due to column moment transfer. ASCE Journal of structural engineering, volume 126, 180-189. 2000.

[11] Model Code fib bulletin 56, Lausanne, The International Federation of Structural Concrete. 2010. 